
ОСТРОГО БИЛИАРНОГО ПАНКРЕАТИТА

\author{
Можейко Л.А. (mozhejko-hist@yandex.ru)
}

УО «Гродненский государственный медицинский университет», Гродно, Беларусь

\begin{abstract}
В настоящем обзоре представлен анализ литературных сведений о токсических воздействиях желчных кислот на ацинарные клетки поджелудочной железы как возможного патогенетического фактора острого билиарного панкреатита. Показано, что на начальной стадии развития острого билиарного панкреатита повреждение ацинарных клеток выражается в нарушении секреторного процесса, активности пищеварительных ферментов, строении и функиии клеточных мембран и органелл. Предполагается, что общим механизмом, который опосредует финальную гибель ацинарных клеток, может быть нарушение кальциевых сигнальных путей, индуцируемое желчными кислотами. Желчные кислоты проникают в ацинарные клетки с помощьью $\mathrm{Na}^{+}$-зависимых и $\mathrm{Na}^{+}$-независимых транспортеров плазматической мембраны, или связываются с G-белковым рецептором желчных кислот. Цитозольные желчные кислоты вызывают устойчивое увеличение концентрации Са $\mathrm{Ca}^{2+}$ через механизмы, способствующие поступлению его в циитозоль из внутриклеточных депо и внеклеточного пространства. Перегрузка Са ${ }^{2+}$ приводит к внутриклеточной активачии трипсиногена, деполяризации митохондрий, истощчению АТФ и к последующей гибели ацинарных клеток.
\end{abstract}

Ключевые слова: желчные кислоты, острый билиарный панкреатит, кальций, ацинарные клетки.

Острый панкреатит (ОП) - полиэтиологическое заболевание поджелудочной железы, которое в совокупности с социальными и биологическими факторами (употребление алкоголя, нерациональное питание и др.) имеет тенденцию к дальнейшему прогрессированию. По данным мировой статистики, доминирующими среди острых панкреатитов являются алкогольный и билиарный панкреатиты $[1,2,3]$. Эпидемиологическое исследование по изучению этиологии и смертности при ОП, проведенное в ряде европейских стран, показало, что имеются значимые различия между ними в преобладании формы панкреатита. Так, в Германии острый алкогольный и билиарный панкреатит встречаются почти с одинаковой частотой (37 и 34 , соответственно), в Венгрии отчетливо преобладает алкогольный панкреатит по сравнению с билиарным (60 и $24 \%$ ), в Италии - билиарный (60 и 13\%) [4]. Более высокий рост заболеваемости отмечается в экономически развитых странах. В Нидерландах и США заболеваемость острым билиарным панкреатитом увеличилась в последнее десятилетие на $35 \%$ [5]. Острый билиарный панкреатит чаще встречается у женщин, чем у мужчин (69 и $31 \%$, соответственно), и реже - у молодых, чем у пожилых людей $[6,7]$.

В течение ряда десятилетий в патогенезе ОП основной остается концепция аутопереваривания поджелудочной железы активированными панкреатическими ферментами $[2,3,8]$. Однако для достижения существенных успехов в лечении этого заболевания современной панкреатологии необходимо знание более точных патофизиологических механизмов ОП. Несмотря на то, что, благодаря научным поискам, представления о патогенезе ОП, в том числе и билиарного, значительно уточнились, детальные молекулярные механизмы активации протеаз, инициирующих развитие заболевания и обостряющих воспалительный процесс, полностью не выяснены.

Цель настоящего обзора - проанализировать современные литературные сведения о моле- кулярных механизмах действия желчных кислот на паренхиму поджелудочной железы при остром билиарном панкреатите.

\section{Этиологические факторы острого билиарного панкреатита}

Пусковым механизмом развития острого билиарного панкреатита является повышенное давление в протоковой системе желчных путей. Оно может быть обусловлено как функциональной (несогласованность в работе сфинктерного аппарата дистальных отделов желчных путей и главного панкреатического протока, гипертонус сфинктера Одди и др.), так и органической патологией (конкременты или сладж, стриктуры общего желчного протока), часто сопровождающей течение желчнокаменной болезни: обнаруживается у $30-60 \%$ пациентов с ОП $[1,9]$. При этом камни могут привести: а) к обструкции панкреатического протока, что блокирует выход панкреатического сока, увеличивает внутридуктальное давление, проницаемость стенки терминальных протоков, активацию ферментов, триггирующих ОП; б) к частичной обтурации ампулы большого дуоденального сосочка, при которой создается соединение между панкреатическим и общим желчным протоком, и желчь может забрасываться в панкреатический проток; в) к закупорке обоих, и панкреатического, и желчного протока, когда рефлюкса желчи не происходит, но обструкция желчного протока может действовать как дополнительный фактор, увеличивающий концентрацию или циркуляцию интерстициальной желчи $[3,10]$. Главная причина развития билиарного панкреатита - заброс желчи в протоки поджелудочной железы, где она взаимодействует с панкреатическими ферментами. В большинстве случаев ОП данного генеза является нетяжелым (отечный панкреатит), имеет абортивное течение (70-80\%). Но в $20-30 \%$ случаев заболевание переходит в тяжелую форму (некротический панкреатит) с летальностью до 40\% [11]. В составе желчи ос- 
новным компонентом являются амфипатические желчные кислоты. Первичные желчные кислоты, холевая и хенодезоксихолевая, конвертируются из холестерина в печени. Большинство желчных кислот комбинируются с эфирами глицина или таурина, образуя глико- и тауросвязанные желчные кислоты, а их соли секретируются в желчь $[8,9,12]$.

\section{Экспериментальные модели острого билиарного панкреатита}

Для изучения механизмов патогенеза острого билиарного панкреатита используются разные экспериментальные модели. Для моделирования ОП, наблюдаемого в клинической ситуации при обструкции протоков, у животных лигируют или общий желчно-панкреатический проток, или панкреатический проток, препятствуя в первом случае току желчи и панкреатического сока, во втором - только панкреатического сока [13]. В большинстве моделей у животных, за исключением опоссума, если лигируется только один панкреатический проток, некротический панкреатит не развивается. У животных наблюдается повреждение поджелудочной железы, характеризующееся атрофией и апоптозом ацинарных и протоковых клеток паренхимы [14]. Если лигируется общий желчно-панкреатический проток, происходит рефлюкс желчи в поджелудочную железу и поднимается внутридуктальное панкреатическое давление. Лигирование общего протока у крыс вызывает острый панкреатит с панкреатическим некрозом и геморрагическими изменениями, который напоминает синдром мультиорганной недостаточности у человека [14]. Однако данные о степени тяжести панкреатита в этой модели крыс противоречивы: она колеблется от легкой до тяжелой. Более того, степень тяжести заболевания зависит от вида животных, используемых в качестве субъекта [13].

ОП, вызванный прямой канюляцией и инфузией желчных кислот в панкреатический проток, является другой моделью, используемой для инициирования билиарного ОП. С 1856 г., когда Bernard добился развития ОП с помощью инфузии желчи и оливкового масла в проток поджелудочной железы собак, разные соли желчных кислот, такие как натрий хенодезоксихолат (CDC), натрий таурохолат (TC), натрий гликодезоксихолиевая кислота (GDC), натрий тауродезоксихолат, 3-сульфат тауролитохолиевая кислота (TLC-S), использовались для того, чтобы вызвать ОП у разных видов экспериментальных животных [14]. Среди этих солей наибольший эффект отмечался при введении натрий таурохолата (ТС-индуцированный панкреатит). Соли желчных кислот вызвали ОП с отеком, геморрагиями и некрозом у большинства животных, таких как кролики, собаки и свиньи. Однако эти животные менее чувствительны к повреждениям, вызывающим полиорганную недостаточность, включая легкие, почки, печень, кишечник, мозг, которые чаще наблюдаются у крыс [13]. Недавно в качестве экспериментальных моделей для индукции острого панкреатита стали использовать мышей с генетическими модификациями и введением TLC-S [15].

Согласно мнению большинства исследователей, обструкция протоков (независимо от причины) приводит прежде всего к повреждению ацинарных клеток [16, 17]. Задержка экзоцитоза зимогенных гранул, содержащих пищеварительные ферменты, через ацинарную мембрану в просвет ацинуса рассматривается в качестве начального механизма патогенеза острого панкреатита. На экспериментальных моделях показано, что в последующем зимогенные гранулы контактируют с внутриклеточными лизосомами и формируют аутофагические вакуоли, содержащие смесь пищеварительных и лизосомальных ферментов. Блок панкреатической секреции через апикальную часть плазмолеммы вызывает миграцию образующихся аутофагических вакуолей в базолатеральную часть клетки и экзоцитоз через неё в интерстициальное пространство. Лизосомальный фермент катепсин В способен активировать конверсию трипсиногена в трипсин. Массивная преждевременная активация трипсина приводит к активации остальных пищеварительных ферментов и аутодигестивному повреждению паренхимы железы.

\section{Токсические эффекты жселчных кислот на}

\section{ацинарные клетки поджелудочной жселезы}

Токсические эффекты желчных кислот как возможного патогенетического фактора на ранней стадии развития острого билиарного панкреатита многие исследователи связывают с повреждениями ацинарных клеток, вызванных нарушением гомеостаза $\mathrm{Ca}^{2+}$. Чрезмерные кальциевые сигналы могут быть причиной внутриклеточной активации трипсиногена, дисфункции митохондрий и других органелл, и в конечном итоге - гибели ацинарных клеток [16, 18$]$.

\section{Изменение гомеостаза $\mathrm{Ca}^{2+}$}

Изучение роли $\mathrm{Ca}^{2+}$ как посредника сигнальных систем привлекает пристальное внимание исследователей. Нарушение строения и функции кальциевых сигнальных систем - причина многих заболеваний. Согласно данным ряда современных исследований, сигналы $\mathrm{Ca}^{2+}$ играют доминирующую роль в секреторном ответе ацинарных клеток на стимуляцию секретагогов как в физиологических, так и патологических условиях [19]. Установлено, что поступление ионов $\mathrm{Ca}^{2+}$ и выработка ферментов в поджелудочной железе идёт параллельно. Освобождение ионов кальция запускает секрецию ферментов. В полярно-дифференцированных ацинарных клетках наибольшее количество $\mathrm{Ca}^{2+}$ депонируется в эндоплазматической сети, локализующейся в базальной части клеток, а в апикальной зоне находятся незначительные запасы $\mathrm{Ca}^{2+}[20]$. Уровень $\mathrm{Ca}^{2+}$ внутри клеток строго контролируется. Показано, что физиологические стимулы (ацетилхолин, холецистокинин) действуют на М-холинорецепторы ацинарных клеток, а высвобождающиеся ионы кальция в роли вторичных мессенджеров стимулируют выделение ферментов через апикальную мембрану клеток. Причём 
этот процесс быстрого повышения уровня $\mathrm{Ca}^{2+}$ регулируется внутриклеточными сигналами, ограниченными только апикальной частью цитоплазмы [20, 21]. Ограниченная в пространстве и времени форма передачи кальциевых сигналов выгодна физиологически, поскольку она допускает их целевое возникновение и применение, а также не приводит к патогенному росту концентрации свободного кальция в других частях клетки. Однако ацинарная клетка может справиться и модулировать свои функции только при быстрых, непродолжительных колебаниях уровня $\mathrm{Ca}^{2+}$. Продемонстрировано, что устойчивый подъём концентрации цитозольного кальция в обеих частях клетки - и апикальной, и базальной, - вызванный гиперстимуляцией секретагогами, приводит к активации трипсина и формированию вакуолей $[7,8]$. Поскольку установлено, что желчные кислоты, такие как TLC-S, TC и TDC, вызывают подобные глобальные осцилляции $\mathrm{Ca}^{2+}$ в панкреатических ацинарных клетках, которые начинаются в их апикальной зоне и распространяются в базальную [24], было сделано заключение, что патогенез острых билиарных панкреатитов может быть связан с токсической перегрузкой цитозольным $\mathrm{Ca}^{2+}$, вызванной желчными кислотами. Изучение молекулярных механизмов воздействия желчных кислот показало их участие в повреждении ацинарных клеток поджелудочной железы.

Желчные кислоты поступают в ацинарные клетки с помощью $\mathrm{Na}^{+}$-зависимых и $\mathrm{Na}+$-независимых белков-переносчиков, локализованных в плазматической мембране апикальной и базолатеральной поверхности клеток [25]. $\mathrm{Na}^{+}-3 \mathrm{a}-$ висимый механизм транспорта опосредуется апикальным натрий-зависимым переносчиком желчной кислоты (NTCP2) и натрий-зависимым анионным переносчиком (SOAT). SOAT, экспрессия которого в ткани поджелудочной железы при изучении ОП на экспериментальных моделях относительно высока, способен транспортировать сульфат-конъюгированные желчные кислоты, такие как TLC-S, чем объясняется чувствительность к ним ацинарных клеток. В отличие от SOAT, NTCP опосредует поступление как глицин- и тауринсвязанных, так и несвязанных желчных кислот у крыс, однако в ацинарных клетках поджелудочной железы мышей его экспрессировать не удалось [26]. $\mathrm{Na}^{+}$-независимый механизм транспорта желчной кислоты опосредуется с помощью $\mathrm{Na}^{+}$-независимого переносчика - ОАТР. В последних исследованиях на моделях экспериментального острого панкреатита у мышей с генетическими модификациями на плазматической мембране апикального полюса ацинарной клетки идентифицирован G-белковый рецептор желчных кислот - Gpbarl, который рассматривается как еще один сигнальный путь, через который может воздействовать желчная кислота [15].

Экспериментально продемонстрировано, что поступившие в ацинарную клетку желчные кислоты, такие как TLC-S, изменяют гомеостаз цитозольного $\mathrm{Ca}^{2+}$. Они индуцируют устойчивый приток $\mathrm{Ca}^{2+}$ в цитозоль из депо в апикальной части клетки и эндоплазматической сети в базальной части, который опосредуется активацией инозитолтрифосфатных (IP3R5) и рианодиновых рецепторов (RyR5) [21]. Кроме того, показано, что желчные кислоты ингибируют АТФ-азу энергетически затратного механизма кальциевого насоса гладкой эндоплазматической сети (SERCA) [25]. Фосфатидилинозитол-3-киназа (РІЗК) и ее продукт фосфатидилинозитол $(3,4,5)$-трифосфат (PIP3) усиливают влияние желчных кислот, угнетая SERCA-зависимое перемещение $\mathrm{Ca}^{2+}$ из цитозоля в эндоплазматическую сеть. Предполагается, что PISK сигнальный путь опосредует индуцируемую желчными кислотами активацию трипсиногена [27]. Снижение $\mathrm{Ca}^{2+}$ в эндоплазматической сети триггирует поступление внеклеточного $\mathrm{Ca}^{2+}$ через каналы плазматической мембраны (SOCs), что является еще одним механизмом увеличения цитозольного $\mathrm{Ca}^{2+}$ [28]. Основной транспорт $\mathrm{Ca}^{2+}$ опосредуется трансмембранным белком - ORA1, который регулируется через взаимодействие со стромальными молекулами - STIM 1и STIM 2, локализованными на мембране эндоплазматической сети. STIM 1 реагируют на снижение $\mathrm{Ca}^{2+}$ в эндоплазматической сети, перемещаются к плазматической мембране, где взаимодействуют с ORAI 1, чтобы открыть каналы SOCs. Ингибиторы ORAI уменьшают местные и системные признаки острого панкреатита на TLC-S-индуцированной модели и рассматриваются в качестве средств, способных предупредить повреждение панкреатических ацинарных клеток у человека [29]. В процесс внутриклеточного повреждения, связанного с накоплением цитозольного $\mathrm{Ca}^{2+}$, вовлекается большинство органелл.

\section{Дисфункция митохондрий}

Как выяснилось, развивающаяся дисфункция митохондрий - одно из центральных звеньев данного процесса. Установлена связь между мембранами эндоплазматической сети и митохондрий, в результате чего образуются так называемые митохондриально-ассоциированные мембранные (MAM) комплексы (IPSRGRP75-VDAC complex) [30]. МAM опосредует перенос $\mathrm{Ca}^{2+}$ из эндоплазматической сети в митохондрии, что необходимо для выполнения их функций - генерации АТФ посредством окислительного фосфорилирования [31]. В митохондриях ацинарных клеток генерируется наибольшее количество энергии в виде АТФ. МАМ комплекс, расположенный в апикальной зоне ацинарных клеток, представляет собой своеобразный буферный слой, снижающий концентрацию свободных кальциевых ионов цитозоля. Для ответа на физиологические стимулы буферной способности этого слоя достаточно. Однако в патологических условиях при устойчивой перегрузке цитозольным $\mathrm{Ca}^{2+}$ данные механизмы недостаточны, что приводит к дисфункции митохондрий и распространению кальция [31]. Увеличенная кальциевая перегрузка способствует открытию неспецифических кана- 
лов, формирующихся во внутренней мембране митохондрий (МРТР), что вызывает понижение потенциала митохондриальной мембраны. Деполяризация митохондрий в конечном счете приводит к внутриклеточному истощению АТФ. Критическая потеря АТФ индуцирует некротическое повреждение ацинарной клетки [32]. На изолированных ацинарных клетках мышей и человека показано, что фармакологическое и генетическое открытие МРТР защищает митохондриальные мембраны, синтез АТФ и предупреждает некроз ацинарной клетки, обусловленный желчь-индуцированным увеличением $\mathrm{Ca}^{2+}$ через IP3R и RyR, вследствие чего MPTP рассматриваются в качестве потенциальной лекарственной мишени средств при остром панкреатите [33].

С другой стороны, желчные кислоты, вызывая устойчивое повышение цитозольного и митохондриального $\mathrm{Ca}^{2+}$, приводят к дозозависимому увеличению продукции реактивных кислородных групп (ROS). В отличие от $\mathrm{Ca}^{2+}$, ROS оказывают малый эффект на потенциал внутренней митохондриальной мембраны, но увеличивают проницаемость наружной мембраны митохондрий и выход митохондриального цитохрома С в цитоплазму, в результате чего активируется каспаза и инициируется апоптоз [34]. Таким образом, $\mathrm{Ca}^{2+}$ и митохондрии не только регулируют функции ацинарных клеток, но и являются важными посредниками их гибели в виде некроза либо апоптоза. Установлено, что при экспериментальном остром панкреатите, вызванном желчными кислотами у крыс и мышей, возможны оба эти повреждения, и от их

\section{Литература}

1. Острый панкреатит: дифференцированная лечебно-диагностическая тактика / М. В. Лысенко [и др.]. - Москва : Литтерра, 2010. - 165 с.

2. Маев, И. В. Болезни поджелудочной железы / И. В. Маев, Ю. А. Кучерявый. - Москва : Медицина, 2008. $-558 \mathrm{c}$.

3. Lankish, P. G. Acute pancreatitis / P. G. Lankish, M. Apte, P. A. Banks // Lancet. - 2015. - Vol. 386, iss. 9988. P. 85-96. - doi: 10.1016/S0140-6736(14)60649-8.

4. Acute Pancreatitis in Five European Countries: Etiology and Mortality / L. Gullo [et al.] // Pancreas. - 2002. Vol. 24, № 3. - P. 223-227.

5. Wilcox, C. M. Role of endoscopic evaluation in idiopathic pancreatitis: a systematic review / C. M. Wilcox, S. Varadarajulu, M. Eloubeidi // Gastrointest. Endosc. 2006. - Vol. 63, iss. 7. - P. 1037-1045. - doi: 10.1016/j. gie.2006.02.024.

6. Ильченко, А. А. Билиарный панкреатит / А. А. Ильченко // Экспер. и клин. гастроэнтер. -2006. - № 1. - С. 10-16.

7. Острый билиарный панкреатит / А. Е. Борисов [и др.] // Анналы хир. гепатол. - 2008. - № 3. - С. 213.

8. Острый панкреатит: морфологические аспекты течения заболевания / В. Г. Фирсова [и др.] // Анналы хир. гепат. - 2014. - Т. 19, № 1. - С. 86-95.

9. Nationwide epidemiological survey of acute pancreatitis in Japan / S. Hamada [et al.] ; Research commit- преобладания зависит дальнейшее течение заболевания [18].

\section{Заключение}

Таким образом, начальная стадия развития острого билиарного панкреатита характеризуется прежде всего повреждением ацинарных клеток поджелудочной железы, которое сопровождается нарушением секреторного процес$\mathrm{ca}$, активацией пищеварительных ферментов, дисфункцией клеточных мембран и органелл. Желчные кислоты проникают в ацинарные клетки с помощью $\mathrm{Na}^{+}$-зависимых или $\mathrm{Na}^{+}$-независимых транспортных белков через апикальную и базолатеральную поверхность плазматической мембраны либо взаимодействуют с G-белковым рецептором желчных кислот. Внутри клеток желчные кислоты вызывают значительное и стойкое увеличение концентрации цитозольного $\mathrm{Ca}^{2+}$, способствуя выходу его из внутриклеточных депо посредством активации инозитолтрифосфатных и рианодиновых рецепторов, с одной

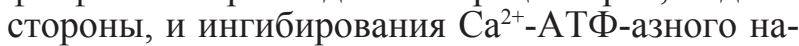
соса саркоэндоплазматической сети, с другой. Кроме того, с помощью трансмембранных белков триггируется поступление в цитозоль внеклеточного $\mathrm{Ca}^{2+}$. Предполагается, что активация MAPK и PISK сигнальных путей опосредует преждевременную активацию трипсиногена. При этом индуцируемый желчными кислотами избыток цитозольного $\mathrm{Ca}^{2+}$ нарушает структуру и функции клеточных мембран и органелл, что в итоге может привести к гибели ацинарных клеток и развитию острого панкреатита.

tee of intractable disease of the pancreas // Pancreas. 2014. - Vol. 43, № 8. - P. 1244-1248. - doi: 10.1097/ MPA.0000000000000200.

10. Lerch, M. M. The role of bile acids in gallstone-induced pancreatitis / M. M. Lerch, A. A. Aghdassi // Gastroenterology. - 2010. - Vol. 138, № 2. - P. 429-433. - doi: 10.1053/j.gastro.2009.12.012.

11. Forsmark, C. E. AGA Institute technical review on acute pancreatitis / C. E. Forsmark, J. Baillie // Gastroenterology. - 2007. - Vol. 13, iss. 5. - P. 2022-2044. - doi: 10.1053/j. gastro.2007.03.065.

12. Vitek, L. The role of bile acids in metabolic regulation/ L. Vitek, M. Haluzik // J. Endocrinology. - 2016. - Vol. 228, iss. 3. - P. 85-96. - doi: 10.1530/JOE-15-0469.

13. Chan, Y. C. Acute pancreatitis: animal models and recent advances in basic research / Y. C. Chan, P. S. Leung // Pancreas. - 2007. - Vol. 34, № 1. - P. 1-14. - doi: 10.1097/01.mpa.0000246658.38375.04.

14. $\mathrm{Su}, \mathrm{K} . \mathrm{H}$. Review of experimental animal models of acute pancreatitis / K. H. Su, C. Cuthbertson, C. Christophi // HPB. - 2006. - Vol. 8, № 4. - P. 264-286. - doi: $10.1080 / 13651820500467358$

15. Biliary acute pancreatitis in mice is mediated by the $G$ protein-coupled cell surface bile acid receptor GPBAR1/ G. Perides [et al.] // Gastroenterology. - 2010. - Vol. 138, № 2. - P. 715-725. - doi: 10.1053/j.gastro.2009.10.052.

16. Sha, R. P. Molecular mechanisms of pancreatic injury / R. P. Sha, A. Saluja // Curr. Opin. Gastroenterol. - 2011. - Vol. 27, № 5. - P. 444-451. 
17. Lankisch, P. G. Acute pancreatitis / P. G. Lankisch, M. Apte, P. A. Banks // Гастроэнтерология СанктПетербурга. - 2017. - № 2. - Р. 3-12.

18. Morihisa, H. Bile Acids and Pancreatic Disease / H. Morihisa, T. Shimosegawa // Bile Acids and Pancreatic Disease / eds.: S. Tazuma, H. Takikawa. - Tokyo : Springer, 2017. - Ch. 12. - P. 169-176. - doi: 10.1007/9784-431-56062-3 12.

19. Petersen, O. H. Polarized calcium signaling in exocrine gland cells / O. H. Petersen, A. V. Tepikin // Annu. Rev. Physiol. - 2008. - Vol. 70. - P. 273-299. - doi: 10.1146/ annurev.physiol.70.113006.100618.

20. Gerasimenko, J. Role of acidic stores in secretory epithelia / J. Gerasimenko, S. Peng, O. Gerasimenko // Cell Calcium. - 2014. - Vol. 55, № 6. - P. 346-354. - doi: 10.1016/j.ceca.2014.04.002.

21. Bile acids induce $\mathrm{Ca}^{2+}$ release from both the endoplasmic reticulum and acidic intracellular calcium stores through activation of inositol trisphosphate receptors and ryanodine receptors / J. V. Gerasimenko [et al.] // J. Biol. Chem. - 2006. - Vol. 281, № 52. - P. 40154-40163. - doi: 10.1074/jbc.M606402200.

22. Kruger, B. The role of intracellular calcium signaling in premature protease activation and the onset of pancreatitis / B. Kruger, E. Albrecht, M. M. Lerch // Am. J. Pathol. 2000. - Vol. 157, № 1. - P. 43-50. - doi: 10.1016/S00029440(10)64515-4.

23. Calcium-dependent enzyme activation and vacuole formation in the apical granular region of pancreatic acinar cells / M. Raraty [et al.] // Proc. Natl. Acad. Sci. U S A. 2000. - Vol. 97, № 24. - P. 13126-13131. - doi: 10.1073/ pnas.97.24.13126.

24. Bile acids induce calcium signals in mouse pancreatic acinar cells: implications for bile-induced pancreatic pathology / S. Voronina [et al.] // J. Physiol. - 2002. - Vol. 540, pt. 1 - P. 49-55.

25. Transporter-mediated bile acid uptake causes $\mathrm{Ca}^{2+}$ dependent cell death in rat pancreatic acinar cells / J. Y. Kim [et al.] // Gastroenterology. - 2002. - Vol. 122, № 7. - P. 1941-1953.

26. Ferdek, P. E. Bile acids induce necrosis in pancreatic stellate cells dependent on calcium entry and sodium-driven bile uptake / P. E. Ferdek // J. Physiol. - 2006. - Vol. 594, № 21. - P. 6147-6164. - doi: 10.1113/JP272774.

27. Phosphatidylinositol 3-kinase facilitates bile acid-induced $\mathrm{Ca}^{2+}$ responses in pancreatic acinar cells / L. Fischer [et al.] // Am. J. Physiol. Gastrointest. Liver Physiol. 2007. - Vol. 292, № 3. - P. 875-886. - doi: 10.1152/ajpgi.00558.2005.

28. Parekh, A. B. Store-operated CRAC channels: function in health and disease / A. B. Parekh // Nat. Rev. Drug Discov. - 2010. - Vol. 9, № 5. - P. 399-410. - doi: 10.1038/ $\operatorname{nrd} 3136$.

29. Inhibitors of ORAI1 prevent cytosolic calcium-associated injury of human pancreatic acinar cells and acute pancreatitis in 3 mouse models / L. Wen [et al.] // Gastroenterology. - 2015. - Vol. 149, № 2. - P. 481-492. - doi: 10.1053/j. gastro.2015.04.015

30. Brito, O. M. An intimate liaison: spatial organization of the endoplasmic reticulum-mitochondria relationship / O. M. Brito, L. Scorrano // EMBO J. - 2010. - Vol. 29, № 16. - P. 2715-2723. - doi: 10.1038/emboj.2010.177.

31. Calcium and apoptosis: ER-mitochondria $\mathrm{Ca}^{2+}$ transfer in the control of apoptosis / P. Pinton [et al.] // Oncogene. 2008. - Vol. 27, № 50. - P. 6407-6418. - doi: 10.1038/ onc. 2008.308
32. Effects of secretagogues and bile acids on mitochondrial membrane potential of pancreatic acinar cells / S. G. Voronina [et al.] // J. Biol. Chem. - 2004. - Vol. 279, № 26. - P. 27327-27338. - doi: 10.1074/jbc.M311698200.

33. Mechanism of mitochondrial permeability transition pore induction and damage in the pancreas: inhibition prevents acute pancreatitis by protecting production of ATP / R. Mukherjee [et al.] // Gut. - 2016. - Vol. 65, № 8. P.1333-1346 - doi: 10.1136/ gutjnl-2014-308553.

34. Gukovsky, I. Organellar dysfunction in the pathogenesis of pancreatitis / I. Gukovsky, S. J. Pandol, A. S. Gukovskaya // Antioxid Redox Signal. - 2011. - Vol. 15, № 10. P. 2699-2710. - doi: 10.1089/ars.2011.4068.

\section{References}

1. Lyisenko MV, Devjatov AS, Ursov SV. Pasko VG, Gricjuk AM. Ostryj pankreatit: differencirovannaja lechebno-diagnosticheskaja taktika. Moskva: Litterra; 2010. 165 p. (Russian).

2. Maev IV, Kucherjavyj JuA. Bolezni podzheludochnoj zhelezy. Moskva: Medicina; 2008. 558 p. (Russian).

3. 3. Lankish PG, Apte M, Banks PA. Acute pancreatitis. Lancet. 2015;386(9988):85-96. doi: 10.1016/S01406736(14)60649-8.

4. Gullo L, Migliori M, Olбh A, Farkas G, Levy P, Arvanitakis C, Lankisch P, Beger H. Acute Pancreatitis in Five European Countries: Etiology and Mortality. Pancreas. 2002;24(3):223-227.

5. Wilcox CM, Varadarajulu S, Eloubeidi M. Role of endoscopic evaluation in idiopathic pancreatitis: a systematic review. Gastrointest. Endosc. 2006;63:1037-1045.

6. Ilchenko AA. Biliarnyj pankreatit. Jeksperimentalnaja $i$ klinicheskaja gastrojentrologija [Experimental and clinical gastroenterology]. 2006;(1):10-16. (Russian).

7. Borisov AE, Kubachev KG, Globin AV, Solonicyn EG, Magomedov JeP. Ostryj biliarnyj pankreatit. Annaly hirurgicheskoj gepatologii. 2008;(3):213. (Russian).

8. Firsova VG, Parshikov VV, Kuznecov SS, Bugrova ML, Jakovleva EI. Ostryj pankreatit: morfologicheskie aspekty techenija zabolevanija. Annaly hirurgicheskoj gepatologii. 2014;19(1):86-95. (Russian).

9. Hamada S, Masamune A, Kikuta K, Hirota M, Tsuji I, Shimosegawa T; Research committee of intractable disease of the pancreas. Nationwide epidemiological survey of acute pancreatitis in Japan. Pancreas. 2014;43(8):12441248. doi: 10.1097/MPA.0000000000000200.

10. Lerch MM, Aghdassi AA. The role of bile acids in gallstone-induced pancreatitis. Gastroenterology. 2010;138(2):429-33. doi: 10.1053/j.gastro.2009.12.012.

11. Forsmark CE, Baillie J. AGA Institute technical review on acute pancreatitis. Gastroenterology. 2007;132(5):20222044. doi: 10.1053/j.gastro.2007.03.065.

12. Vitek L, Haluzik M. The role of bile acids in metabolic regulation. J. Endocrinology. 2016;228(3):85-96. doi: 10.1530/JOE-15-0469.

13. Chan YC, Leung PS. Acute pancreatitis: animal models and recent advances in basic research. Pancreas. 2007;34(1):114. doi: 10.1097/01.mpa.0000246658.38375.04.

14. Su KH, Cuthbertson C, Christophi C. Review of experimental animal models of acute pancreatitis. $H P B$. 2006;8(4):264-86. doi: 10.1080/13651820500467358.

15. Perides G. Biliary acute pancreatitis in mice is mediated by the $G$ protein-coupled cell surface bile acid receptor GPBAR1. Gastroenterology. 2010;138(2):715-725. doi: 10.1053/j.gastro.2009.10.052. 
16. Sha RP, Saluja A. Molecular mechanisms of pancreatic injury. Curr. Opin. Gastroenterol. 2011;27(5):444-451.

17. Lankisch PG, Apte M, Banks PA. Acute pancreatitis. Gastrojenterologija Sankt-Peterburga. 2017;(2):3-12.

18. Morihisa H, Shimosegawa T. Bile Acids and Pancreatic Disease. In: Tazuma S, Takikawa H, editors. Bile Acids in Gastroenterology. Ch. 12. Tokyo: Springer; 2017. p. 169176. doi: 10.1007/978-4-431-56062-3_12.

19. Petersen $\mathrm{OH}$, Tepikin AV. Polarized calcium signaling in exocrine gland cells. Annu. Rev. Physiol. 2008;70:273299. doi: 10.1146/annurev.physiol.70.113006.100618.

20. Gerasimenko J, Peng S, Gerasimenko O. Role of acidic stores in secretory epithelia. Cell Calcium. 2014;55(6):346354. doi: 10.1016/S0002-9440(10)64515-4.

21. Gerasimenko JV. Bile acids induce $\mathrm{Ca}^{2+}$ release from both the endoplasmic reticulum and acidic intracellular calcium stores through activation of inositol trisphosphate receptors and ryanodine receptors. J. Biol Chem. 2006;281(52):40154-40163. doi: 10.1074/jbc. M606402200.

22. Kruger B, Albrecht E, Lerch MM. The role of intracellular calcium signaling in premature protease activation and the onset of pancreatitis. Am. J. Pathol. 2000;157(1):43-50. doi: 10.1016/S0002-9440(10)64515-4.

23. Raraty M, Ward J, Erdemli G, Vaillant C, Neoptolemos JP, Sutton R, Petersen OH. Calcium-dependent enzyme activation and vacuole formation in the apical granular region of pancreatic acinar cells. Proc. Natl. Acad. Sci. U S A. 2000;97(24):13126-13131. doi: 10.1073/ pnas.97.24.13126.

24. Voronina S. Bile acids induce calcium signals in mouse pancreatic acinar cells: implications for bile-induced pancreatic pathology. J. Physiol. 2002;540(Pt 1):49-55.

25. Kim JY. Transporter-mediated bile acid uptake causes $\mathrm{Ca}^{2+}$-dependent cell death in rat pancreatic acinar cells. Gastroenterology. 2002;122(7):1941-1953.

26. Ferdek PE. Bile acids induce necrosis in pancreatic stellate cells dependent on calcium entry and sodium-driven bile uptake. J. Physiol. 2006;594(21):6147-6164. doi: 10.1113/JP272774.

27. Fischer L. Phosphatidylinositol 3-kinase facilitates bile acid-induced $\mathrm{Ca}^{2+}$ responses in pancreatic acinar cells. $\mathrm{Am}$.
J. Physiol. Gastrointest. Liver Physiol. 2007;292(3):87586. doi: 10.1152/ajpgi.00558.2005.

28. Parekh AB. Store-operated CRAC channels: function in health and disease. Nat. Rev. Drug Discov. 2010;9(5):399410. doi: $10.1038 / \mathrm{nrd} 3136$.

29. Wen L, Voronina S, Javed MA, Awais M, Szatmary P, Latawiec D, Chvanov M, Collier D, Huang W, Barrett J, Begg M, Stauderman K, Roos J, Grigoryev S, Ramos S, Rogers E, Whitten J, Velicelebi G, Dunn M, Tepikin AV, Criddle DN, Sutton R. Inhibitors of ORAI1 prevent cytosolic calcium-associated injury of human pancreatic acinar cells and acute pancreatitis in 3 mouse models. Gastroenterology. 2015;149(2):481-492. doi: 10.1053/j. gastro.2015.04.015.

30. Brito OM, Scorrano L. An intimate liaison: spatial organization of the endoplasmic reticulum-mitochondria relationship. EMBO J. 2010;29(16):2715-23. doi: 10.1038/ emboj.2010.177.

31. Pinton P, Giorgi C, Siviero R, Zecchini E, Rizzuto R. Calcium and apoptosis: ER-mitochondria $\mathrm{Ca}^{2+}$ transfer in the control of apoptosis. Oncogene. 2008;27(50):64076418. doi: 10.1038/onc.2008.308.

32. Voronina SG, Barrow SL, Gerasimenko OV, Petersen $\mathrm{OH}$, Tepikin AV. Effects of secretagogues and bile acids on mitochondrial membrane potential of pancreatic acinar cells. J. Biol Chem. 2004;279(26):27327-27338. doi: 10.1074/jbc.M311698200.

33. Mukherjee R, Mareninova OA, Odinokova IV, Huang W, Murphy J, Chvanov M, Javed MA, Wen L1, Booth DM, Cane MC, Awais M, Gavillet B, Pruss RM, Schaller S, Molkentin JD, Tepikin AV, Petersen OH, Pandol SJ, Gukovsky I, Criddle DN, Gukovskaya AS, Sutton R. Mechanism of mitochondrial permeability transition pore induction and damage in the pancreas: inhibition prevents acute pancreatitis by protecting production of ATP. Gut. 2016;65(8):1333-1346. doi: 10.1136/ gutjnl-2014-308553.

34. Gukovsky I, Pandol SJ, Gukovskaya AS. Organellar dysfunction in the pathogenesis of pancreatitis. Antioxid Redox Signal. 2011;15(10):2699-2710. doi: 10.1089/ ars.2011.4068.

\title{
BILE ACIDS AS A PATHOGENETIC FACTOR OF ACUTE BILIARY PANCREATITIS
}

\author{
Mozheiko L. A.
}

Educational Institution "Grodno State Medical University", Grodno, Belarus

The review presents an analysis of the literature on the toxic effects of bile acids on the acinar cells of the pancreas as a possible pathogenetic factor in acute biliary pancreatitis. It is shown that at an early stage of acute biliary pancreatitis the damage to the acinar cells is manifested in disturbances of the secretory process, activity of the digestive enzymes, as well as in the disturbances in the structure and function of cell membranes and organelles. It is assumed that the general mechanism that mediates the final death of the acinar cells might be aberrant calcium signaling pathways induced by bile acids. Bile acids can be taken up by the acinar cells through $\mathrm{Na}^{+}$-dependent and $\mathrm{Na}^{+}$-independent transporters located at the plasma membrane, or by a G-protein-coupled receptor for bile acids. Cytosolic bile acids induce sustained increase in calcium concentration via mechanisms that involve depletion of intracellular $\mathrm{Ca}^{2+}$ stores and activation of $\mathrm{Ca}^{2+}$ entry. Overload with $\mathrm{Ca}^{2+}$ leads to intracellular trypsinogen activation, mitochondrial depolarization, depletion of ATP and subsequent death of the acinar cells.

Keywords: bile acids, acute biliary pancreatitis, calcium, acinar cells. 